\title{
Evaluation of cardiovascular disease risk factors in patients with mycosis fungoides
}

\author{
Fatma Pelin Cengiz ${ }^{1}$ \\ Nazan Emiroglu ${ }^{2}$
}

DOI: http://dx.doi.org/10.1590/abd1806-4841.20153352

\begin{abstract}
BACKGROUND: Mycosis fungoides, the most common subtype of cutaneous T-cell lymphoma, is more common in patients aged 45-55.

OвјестіVE: Cardiovascular risk factors have been investigated in several skin diseases. However, the relation between cardiovascular diseases and mycosis fungoides remains unclear. Therefore, the aim of this study was to assess cardiovascular risk factors in patients with mycosis fungoides.

MeTHODS: 32 patients with mycosis fungoides and 26 healthy controls were enrolled in the study. Glucose, total cholesterol, high-density lipoprotein cholesterol, triglyceride, homocystein, high sensitivity C-reactive protein, low-density lipoprotein cholesterol, were measured in the sera of patients.

RESULTS: Patients had significantly higher high-sensitivity C-reactive protein, homocysteine, low-density lipoprotein - cholesterol, total cholesterol $(\mathrm{p}=0.032)(\mathrm{p}<0.001)(\mathrm{p}=0.001)(\mathrm{p}<0.001)$. There was a positive correlation between the levels of homocysteine and total cholesterol $(p=0.001, r=+0.431)$. Additionally, a significantly positive correlation was found between the levels of high-sensitivity $C$-reactive protein and low-density lipoprotein - cholesterol $(p=0.014, r=+0.320)$ in patient group. ConcLusions: Patients with mycosis fungoides had significantly higher levels of total-cholesterol, low-density lipoprotein -cholesterol, homocysteine and high-sensitivity C-reactive protein than healthy subjects. The present study has demonstrated an increased rate of cardiovascular risk in patients with mycosis fungoides. Even though the etiology of these associations is elusive, dermatologists should be sensitized to investigate metabolic derangements in patients with mycosis fungoides, in order to lessen mortality and comorbidity with a multidisciplinary approach.
\end{abstract}

Keywords: Cardiology; Cardiovascular diseases; Mycosis fungoides

\section{INTRODUCTION}

Mycosis fungoides (MF) is the most common form of cutaneous T-cell lymphomas. Annual incidence of mycosis fungoides is approximately 0.36 cases per 100,000 inhabitants. It usually presents in patients aged $45-55$, but has also been diagnosed in children and adolescents. It is 50\% more common in black patients. ${ }^{1}$ Mycosis fungoides has an indolent course, from patch to tumor stage. In advanced stages, there may be involvement of lymph nodes and internal organs, or the disease may transform into a higher-grade lymphoma. ${ }^{2}$

Several studies have demonstrated the increased cardiovascular risk in patients with dermatologic diseases. In particular, psoriasis is a disease that was associated with metabolic syndrome and increased cardiovascular risk. ${ }^{3,4}$ Furthermore, there are studies investigating the relationship between cardio- logic risk factors and dermatologic diseases, such as androgenetic alopecia, lichen planus and acne rosacea. ${ }^{5,67}$ To the best of our knowledge, cardiovascular risk factors in patients with MF have not been investigated in the literature. The knowledge of the association between MF and cardiovascular comorbidities can help in early management and modification of risk factors, minimize the impact of the cardiovascular comorbidities, and improve patients' longterm situations. Therefore, we aim to investigate cardiologic risk factors in patients without signs of cardiologic disease.

\section{MATERIALS AND METHODS Subjects}

This case control study was conducted at the Department of Dermatology of Diskapi Yildirim

\footnotetext{
Received on 29.12.13.

Approved by the Advisory Board and accepted for publication on 27.02.2014.

Work performed at the Diskapi Yildirim Beyazit Training and Research Hospital - Ankara, Turkey.

Financial support: none.

Conflict of interests: none.

Kutahya Tavsanli State Hospital - Kutahya Tavsanli, Turkey. 
Beyazit Training and Research Hospital, performed between January 2011 and November 2011. Study populations were selected by specific selection criteria. Of the total 58 subjects, 32 patients with MF (mean age: $52.31 \pm 10.95$ ) were all newly-diagnosed cases and lifetime non-smokers, and free of drug, alcohol, or antioxidant supplement consumption, and of any metabolic disease. None of the patients had any other significant disease or malignancy, except for MF. Twenty-six age- and sex-matched, healthy controls (mean age: $51.38 \pm 11.67$ ), were selected by incidence density sampling. The body mass index (BMI) of each patient was calculated. BMI of 18.5-24.9 indicated normal weight, 25-29.9 overweight, $>30.0$ obesity.

Diagnosis of MF was confirmed by clinical observations and histopathological and immunocytochemical examinations of skin biopsy. The patients were classified into five groups according to the 2005 WHO/EORTC system [8]: 19 patients with MF stage IA, 4 patients with stage IB, 2 patients with stage IIB, and 7 patients with stage III. None of the patients presented with visceral organ involvement.

The study protocol was approved by the local ethics committee, and the participants provided written consent.

\section{Sample Preparation}

Blood samples were obtained in the morning after 12 hours of fasting.

\section{Biochemical analysis}

We measured the serum glucose, total cholesterol, high-density lipoprotein cholesterol (HDLc), triglyceride (TG), homocysteine, high sensitivity Creactive protein (HsCRP), low-density lipoproteincholesterol (LDLc), as cardiac risk factors. Serum concentrations of glucose, triglyceride, total and LDLcholesterol were determined by enzymatic procedures. Glucose, total cholesterol, HDLc, LDLc, triglyceride levels were expressed in $\mathrm{mg} / \mathrm{dL}$. Serum high sensitivity CRP (HsCRP) was measured by immunoturbidimetric assay. HsCRP levels were expressed in $\mathrm{mg} / \mathrm{L}$. Blood for measuring homocysteine was collected in tubes containing EDTA and kept on ice until centrifuged (3500 $\mathrm{rpm} / \mathrm{min}$ for $15 \mathrm{~min})$. Homocysteine level was evaluated with immunoassay (Immulate 2000 (reference range, 5.0-12 $\mu \mathrm{ol} / \mathrm{l}$ ).

\section{Statistical analysis}

All statistical calculations were performed using the Statistical Package for Social Sciences (SPSS) v15.0 for Microsoft Windows. The results are expressed as the mean \pm standard deviation. Continuous variables were compared using Student's $\mathrm{t}$ test and Mann-Whitney U-test. One-way ANOVA test was used for comparing variables in patients with different stages of MF. For correlations between variables, Spearman correlation coefficients were estimated. $\mathrm{P}<0.05$ was regarded as statistically significant.

\section{RESULTS}

The clinical data of the MF patients are shown in Table 1 . There were no statistically significant differences between patients with MF and healthy subjects with respect to age and gender $(p>0.05)$. There was no statistically significant difference for the mean value of BMI between patients $(24.96 \pm 1.55)$ and the control group $(22.81 \pm 2.15)$.

The biochemical analyses of both groups were compared. The mean value of serum LDLc was 144.65 $\pm 33.69 \mathrm{mg} / \mathrm{dl}$ in the patient group, while it was 117.61 $\pm 22.42 \mathrm{mg} / \mathrm{dl}$ in the control group. There was a statistically significant difference in serum LDLc between groups $(p=0.001)$. The mean value of serum total cholesterol was significantly higher in patients with MF $(214.56 \pm 36.48 \mathrm{mg} / \mathrm{dl})$ than in healthy controls $(142.30$ $\pm 28.92 \mathrm{mg} / \mathrm{dl})(p<0.001)$. Patients had significantly higher HsCRP $(4.43 \pm 4.74$ vs $2.20 \pm 1.19 \mathrm{mg} / \mathrm{L}, p=$ $0.032)$ and homocysteine $(11.88 \pm 4.80$ vs $5.58 \pm 1.64$ $\mu \mathrm{mol} / 1, p<0.001)$ values than the control group.

No differences were found in TG, HDLc and glucose levels between both groups $(p=0.906)$ $(p=0.843)(p=0.432)$ (Table 2).

In patients with $\mathrm{MF}$, there was a positive correlation between the levels of homocysteine and total cholesterol $(p=0.001, \mathrm{r}=+0.431)$. Additionally, a significantly positive correlation was found between the levels of HsCRP and LDLc $(p=0.014, r=+0.320)$ in the patient group.

Further, there was no correlation between the stage of the disease and homocysteine, HsCRP, LDLc and total cholesterol $(p=0.312)(p=0.135)(p=0.552)$ $(p=0.620)$.

\section{DISCUSSION}

Coronary heart disease (CHD) is the narrowing or blockage of the coronary arteries, usually caused by atherosclerosis, which is composed of cholesterol and atheroma plaques inside the arteries. These plaques can decrease blood flow by causing abnormal artery tone and function. Decreased blood flow and inadequate blood supply causes angina. If these plaques completely obstruct the artery to a portion of the heart muscle, myocardial infarct may occur. Coronary artery disease is the most common cause of death in the United States; 600,000 people die each year from CHD. ${ }^{9}$ Prevention is the key to treating CHD. Coronary artery disease has a number of well determined risk factors. The most common risk factors include smoking, family history, hypertension, obesi- 
TABle 1: Clinical data of MF patients

\begin{tabular}{|c|c|c|c|c|c|c|}
\hline No & Age & Gender & BMI & Stage & $\begin{array}{l}\text { Medical History } \\
\text { of Drugs }\end{array}$ & $\begin{array}{l}\text { Medical History } \\
\text { of Disease }\end{array}$ \\
\hline 1 & 41 & $\mathrm{M}$ & 23.6 & $1 \mathrm{~A}$ & None & Gastritis \\
\hline 2 & 53 & $\mathrm{M}$ & 24.2 & 3 & None & None \\
\hline 3 & 48 & $\mathrm{~F}$ & 25.1 & $1 \mathrm{~A}$ & None & None \\
\hline 4 & 41 & $\mathrm{M}$ & 26.2 & 3 & None & None \\
\hline 5 & 55 & $\mathrm{~F}$ & 23.9 & $1 \mathrm{~A}$ & Emollient & None \\
\hline 6 & 65 & $\mathrm{M}$ & 22.8 & $1 \mathrm{~A}$ & None & Urolithiasis \\
\hline 7 & 50 & $\mathrm{M}$ & 21.5 & $1 \mathrm{~A}$ & None & None \\
\hline 8 & 24 & M & 24.6 & $1 \mathrm{~B}$ & Topical antifungal & None \\
\hline 9 & 70 & M & 23.6 & 3 & Emollient & None \\
\hline 10 & 51 & $\mathrm{~F}$ & 26.8 & $1 \mathrm{~A}$ & None & None \\
\hline 11 & 55 & M & 28.2 & $1 \mathrm{~A}$ & None & None \\
\hline 12 & 36 & M & 25.6 & 3 & None & None \\
\hline 13 & 63 & $\mathrm{M}$ & 24.7 & $2 \mathrm{~B}$ & None & None \\
\hline 14 & 73 & M & 23.9 & $1 \mathrm{~A}$ & None & None \\
\hline 15 & 64 & $\mathrm{M}$ & 25.6 & $1 \mathrm{~A}$ & None & None \\
\hline 16 & 49 & $\mathrm{~F}$ & 26.3 & 1B & None & Caesarean \\
\hline 17 & 58 & $\mathrm{~F}$ & 26.3 & $1 \mathrm{~A}$ & None & None \\
\hline 18 & 64 & $\mathrm{~F}$ & 27.3 & $2 \mathrm{~B}$ & None & None \\
\hline 19 & 57 & $\mathrm{~F}$ & 27.2 & 3 & None & None \\
\hline 20 & 49 & $\mathrm{~F}$ & 24.9 & $1 \mathrm{~A}$ & None & None \\
\hline 21 & 57 & F & 26.4 & 3 & None & None \\
\hline 22 & 53 & M & 25.7 & $1 \mathrm{~A}$ & None & None \\
\hline 23 & 46 & M & 25.1 & $1 \mathrm{~A}$ & None & None \\
\hline 24 & 65 & F & 22.8 & $1 \mathrm{~A}$ & None & None \\
\hline 25 & 43 & $\mathrm{~F}$ & 22.9 & 3 & None & Caesarean \\
\hline 26 & 56 & F & 23.4 & $1 \mathrm{~B}$ & None & None \\
\hline 27 & 40 & F & 23.6 & $1 \mathrm{~A}$ & None & None \\
\hline 28 & 48 & F & 25.8 & $1 \mathrm{~A}$ & None & None \\
\hline 29 & 45 & M & 26.4 & $1 \mathrm{~A}$ & None & None \\
\hline 30 & 68 & F & 25.9 & $1 \mathrm{~B}$ & None & None \\
\hline 31 & 39 & F & 24.9 & $1 \mathrm{~A}$ & None & Caesarean \\
\hline 32 & 48 & M & 23.8 & $1 \mathrm{~A}$ & None & None \\
\hline
\end{tabular}

TABLE 2: Baseline characteristics of the study groups

\begin{tabular}{llll}
\hline & Patient & Control & $\mathrm{p}$ Value \\
\hline Serum homocysteine $(\mu \mathrm{mol} / \mathrm{l})$ & $11.88 \pm 4.80$ & $5.58 \pm 1.64$ & $\mathrm{p}<0.001$ \\
& $($ Median Value: 12.50$)$ & $($ Median Value: 6.40$)$ & \\
Serum HsCRP $(\mathrm{mg} / \mathrm{L})$ & $4.43 \pm 4.74$ & $2.20 \pm 1.19$ & $\mathrm{p}=0.032$ \\
& $($ Median Value: 2.51$)$ & $($ Median Value: 2.15$)$ & \\
Fasting Blood Glucose $(\mathrm{mg} / \mathrm{dl})$ & $94.34 \pm 33.08$ & $88.92 \pm 12.31$ & $\mathrm{p}=0.432$ \\
& (Median Value: 92$)$ & $($ Median Value: 80$)$ & \\
Triglycerides $(\mathrm{mg} / \mathrm{dl})$ & $126.56 \pm 25.15$ & $125.69 \pm 30.65$ & $\mathrm{p}=0.906$ \\
& $($ Median Value: 130$)$ & $($ Median Value: 118$)$ & \\
Serum HDL $(\mathrm{mg} / \mathrm{dl})$ & $57.84 \pm 9.84$ & $57.30 \pm 10.62$ & $\mathrm{p}=0.843$ \\
& $($ Median Value: 55$)$ & $($ Median Value: 50$)$ & \\
Serum LDL $(\mathrm{mg} / \mathrm{dl})$ & $144.65 \pm 33.69$ & $117.61 \pm 22.42$ & $\mathrm{p}=0.001$ \\
& $($ Median Value: 140$)$ & $($ Median Value: 110$)$ & \\
Total cholesterol $(\mathrm{mg} / \mathrm{dl})$ & $214.56 \pm 36.48$ & $142.30 \pm 28.92$ & $\mathrm{p}<0.001$ \\
& $($ Median Value: 220$)$ & $($ Median Value: 130$)$ & \\
\hline
\end{tabular}


ty, diabetes, high alcohol consumption, lack of exercise, stress, and hyperlipidemia. ${ }^{10}$

With the recognition of the crucial link between arterial damage, inflammatory processes, and coronary atherosclerosis, HsCRP estimation has assumed a vital role in cardiac risk assessment. HsCRP is a global indicator of future vascular events in adults without any previous history of cardiovascular disease (CVD), with acceptable precision levels down to or below $0.3 \mathrm{mg} / \mathrm{L}$. HsCRP enhances risk assessment and therapeutic outcomes in primary CVD prevention, particularly in patients with LDL levels of $<160$ $\mathrm{mg} / \mathrm{dL}^{11,12}$ According to the American Heart Association (AHA) and Centers for Disease Control and Prevention (CDC), HsCRP levels of $>3 \mathrm{mg} / \mathrm{L}$ predict a high risk of $\mathrm{CHD}$.

Homocysteine is an aminoacid that is produced by the body. A high level of homocysteine creates a tendency toward endothelial injury, leading to vascular inflammation, which in turn may lead to atherogenesis. Therefore, hyperhomocysteinemia is a possible risk factor for CHD. ${ }^{13}$ Common levels in Western populations are 10 to $12 \mu \mathrm{mol} / 1$.

MF is the most common variant of cutaneous lymphomas. It may entail patch, plaque and tumor phases $^{1}$, and is incurable in most patients, with the exception of those with stage IA of the disease. Patients with stage IA MF who undergo treatment have an overall life expectancy similar to that of age, sex and race-matched controls.

Late-stage MF is associated with increasing immunosuppression, and death most often results from systemic infection. ${ }^{14}$ As coronary artery disease is the most common cause of death in the world, detecting the possible risk factors and possible relations between MF and CHD is important to identify patients at risk of coronary artery disease and decrease the mortality rates in patients with MF.

Many studies have linked dermatological diseases to the increased risk of cardiovascular disease. Among all cutaneous disorders, psoriasis has been found to have the strongest association with cardiovascular diseases. The first study on the relationship between psoriasis and cardiovascular diseases was performed by McDonald and Calabresi in $1978 .^{3}$
In addition, psoriasis patients with a higher psoriasis area severity index score had a tendency for metabolic syndrome. ${ }^{4}$ The other dermatologic diseases with an increased risk of cardiovascular disease were androgenetic alopecia acanthosis nigricans, skin tags, acne inversa, lichen planus and systemic lupus erythematosus. ${ }^{5,15-18}$ According to the results of Shu $X$ et al. and Rosengren $\mathrm{A}$ et al., in non-melanoma skin cancer, diabetes mellitus type- 1 and high blood pressure have been implicated as high risk factors in the process of carcinogenesis. ${ }^{19,20}$

\section{CONCLUSION}

This is the first study investigating the relationship between cardiovascular disease and MF in the literature. It has demonstrated an increased rate of cardiovascular risk in patients with $\mathrm{MF}$, who had significantly higher levels of total-cholesterol, LDL-cholesterol, homocysteine and HsCRP than those of healthy subjects. In our study, patients with MF did not have a medical history of disease or systemic therapy, and were non-smokers. Therefore, the levels of HsCRP, homocysteine, LDLc and total cholesterol were neither the results of systemic drugs nor smoking. We did not find any relation between age, gender, stage of disease and the parameters. Further, there were positive, marked correlations between HsCRP and LDLc, as well as between homocysteine and total cholesterol.

Intra-abdominal fat is capable of secreting adipocytokines that have many effects on inflammation, glucose metabolism and vascular endothelial biology. ${ }^{21}$ Visceral adipose tissue reveals cytokines, such as tumor necrosis factor alpha (TNF- $\alpha$ ) and interleukin-6 (IL-6). These cytokines were also found to be elevated in lesional skin of MF patients. ${ }^{22,23}$ The pathogenesis of MF remains unclear, though it may be related to oxidative stress. As a result of oxidative stress and chronic inflammation, these cytokines are secreted. We hold that both diseases share a similar pathogenesis via those cytokines. Although the etiology of these associations is elusive, dermatologists should be sensitized to investigate metabolic derangements in patients with MF, in order to reduce mortality and comorbidity, with a multidisciplinary approach. $\square$ 


\section{REFERENCES}

1. Morales-Suárez-Varela MM, Olsen J, Johansen P, Kaerlev L, Guénel P, Arveux P, et al. Occupational risk factors for mycosis fungoides: a European multicenter case-control study. J Occup Environ Med. 2004;46:205-11.

2. Edelson RL. Cutaneous T cell lymphoma. The helping hand of dendritic cells. Ann N Y Acad Sci. 2001;941:1-11.

3. McDonald CJ, Calabresi P. Psoriasis and occlusive vascular disease. Br J Dermatol. 1978;99:469-75.

4. Sommer DM, Jenisch S, Suchan M, Christophers E, Weichenthal M. Increased prevalence of the metabolic syndrome in patients with moderate to severe psoriasis. Arch Dermatol Res. 2006;298:321-8.

5. Severi G, Sinclair R, Hopper JL, English DR, McCredie MR, Boyle P, et al. Androgenetic alopecia in men aged 40-69 years: Prevalence and risk factors. $\mathrm{Br} \mathrm{J}$ Dermatol. 2003;149:1207-13.

6. Dreiher J, Shapiro J, Cohen AD. Lichen planus and dyslipidaemia: A case-control study. Br J Dermatol. 2009;161:626-9.

7. Duman N, Ersoy Evans S, Atakan N. Rosacea and cardiovascular risk factors: a case control study. J Eur Acad Dermatol Venereol. 2013. [Epub ahead of print]

8. Willemze R, Jaffe ES, Burg G, Cerroni L, Berti E, Swerdlow SH, et al. WHO-EORTC classification for cutaneous lymphomas. Blood. 2005;105:3768-85.

9. Kochanek KD, Xu JQ, Murphy SL, Miniño AM, Kung HC. Deaths: final data for 2009. National vital statistics reports. 2011;60:1-51.

10. Wilson PW, D'Agostino RB, Levy D, Belanger AM, Silbershatz H, Kannel WB. Prediction of coronary heart disease using risk factor categories. Circulation. 1998;97:1837-47.

11. Pearson TA, Mensah GA, Alexander RW, Anderson JL, Cannon RO 3rd, Criqui M, et al. Markers of inflammation and cardiovascular disease: application to clinical and public health practice: A statement for healthcare professionals from the Centers for Disease Control and Prevention and the American Heart Association. Circulation. 2003;107:499-511.

12. Ridker PM; JUPITER Study Group. Rosuvastatin in the primary prevention of cardiovascular disease among patients with low levels of low-density lipoprotein cholesterol and elevated high-sensitivity C-reactive protein: rationale and design of the JUPITER trial. Circulation. 2003;108:2292-7.

13. Pancharuniti N, Lewis CA, Sauberlich HE, Perkins LL, Go RC, Alvarez J0, et al. Plasma homocyst(e)ine, folate, and vitamin B-12 concentrations and risk for earlyonset coronary artery disease. Am J Clin Nutr. 1994;59:940-8.

14. Olsen EA, Whittaker S, Kim YH, Duvic M, Prince HM, Lessin SR, et al. Clinical end points and response criteria in mycosis fungoides and Sézary syndrome: a consensus statement of the International Society for Cutaneous Lymphomas, the United States Cutaneous Lymphoma Consortium, and the Cutaneous Lymphoma Task Force of the European Organisation for Research and Treatment of Cancer. J Clin Oncol. 2011;29:2598-607.

15. Stuart CA, Smith MM, Gilkison CR, Shaheb S, Stahn RM. Acanthosis Nigricans among native Americans: An indicator of high diabetes risk. Am J Public Health. 1994;84:1839-42.

16. Sudy E, Urbina F, Maliqueo M, Sir T. Screening of glucose/insulin metabolic alterations in men with multiple skin tags on the neck . J Dtsch Dermatol Ges. 2008:6:8525, 852-6.

17. Sabat R, Chanwangpong A, Schneider-Burrus S, Metternich D, Kokolakis G, Kurek A, et al. Increased prevalence of metabolic syndrome in patients with acne inversa. PLoS One. 2012;7:e31810.
18. Ward MM. Premature morbidity from cardiovascular and cerebrovascular diseases in women with systemic lupus erythematosus. Arthritis Rheum. 1999;42:338-46.

19. Shu X, Ji J, Li X, Sundquist J, Sundquist K, Hemminki K. Cancer risk among patients hospitalized for Type 1 diabetes mellitus: A population-based cohort study in Sweden. Diabet Med. 2010;27:791-7.

20. Rosengren A, Himmelmann A, Wilhelmsen L, Branehög I, Wedel H. Hypertension and long-term cancer incidence and mortality among Swedish men. J Hypertens. 1998;16:933-40

21. Sterry W, Strober BE, Menter A; International Psoriasis Council. Obesity in psoriasis: the metabolic, clinical and therapeutic implications. Report of an interdisciplinary conference and review. Br J Dermatol. 2007;157:649-55.

22. Seif El Nasr H, Shaker OG, Fawzi MM, El-Hanafi G. Basic fibroblast growth factor and tumour necrosis factor alpha in vitiligo and other hypopigmented disorders: suggestive possible therapeutic targets. J Eur Acad Dermatol Venereol. 2013;27:103-8.

23. Lawlor F, Smith NP, Camp RD, Bacon KB, Black AK, Greaves MW, et al. Skin exudate levels of interleukin 6 , interleukin 1 and other cytokines in mycosis fungoides. $\mathrm{Br}$ J Dermatol. 1990;123:297-304.
MAILING ADDRESS:
Fatma Pelin Cengiz
Kars State Hospital
Örnek Mh. Kars Devlet
Hastanesi 36200 Merkez
Kars, Turquia.
E-mail: fpelinozgen@hotmail.com

How to cite this article: Cengiz FP, Emiroglu N. Evaluation of cardiovascular disease risk factors in patients with mycosis fungoides. An Bras Dermatol. 2015;90(1):36-40. 